\title{
A VULNERABILIDADE DO FIEL-CONSUMIDOR DIANTE DO PRINCÍPIO DA LIBERDADE RELIGIOSA
}

\author{
http://dx.doi.org/10.21527/2176-6622.2019.52.224-235
}

Recebido em: 28/7/2019

Modificações requeridas em: 26/10/2019

Aceito em: 5/11/2019

Rayssa Rodrigues Lopes

Mestranda no Programa de Pós-Graduação Stricto Sensu em Proteção dos Direitos Fundamentais da Universidade de Itaúna/MG. Especialista em Direito do Consumidor (Faculdade Damásio). Bacharel em Direito pela Universidade de Itaúna. http://lattes.cnpq.br/8771613963709490. rayssarl@yahoo.com.br

\section{Márcio Eduardo Senra Nogueira Pedrosa Morais}

Doutor e mestre em Teoria do Direito (PUC-MG). Professor da Graduação e do Programa de Pós-Graduação Stricto Sensu em Direito da Universidade de Itaúna. Professor da Faculdade de Pará de Minas-MG. http://lattes.cnpq.br/4987303044300524. marcioeduardopedrosamorais@gmail.com

\section{RESUMO}

O presente artigo analisa a polêmica da indústria cultural religiosa e os possíveis meios de se assegurar o direito do fiel-consumidor quando da existência de algum abuso da autoridade religiosa, tida como fornecedora de bens e serviços, contrariando o princípio da liberdade religiosa. Conclui-se ser o Código de Defesa do Consumidor (1990) a principal fonte legislativa à qual o fiel-consumidor pode recorrer para solucionar conflitos relacionados à falha na prestação de serviços religiosos prometidos, consistindo a oferta onerosa uma ofensa à liberdade religiosa.

Palavras-chave: Direito do consumidor. Liberdade religiosa. Relação de consumo religiosa. Vulnerabilidade do fiel-consumidor.

\section{THE VULNERABILITY OF THE FAITHUFL CONSUMER FACING THE PRINCIPLE OF RELIGIOUS FREEDOM}

\section{ABSTRACT}

This article examines the controversy of the religious cultural industry and the possible ways to ensure the right of the faithful consumer when there is any religious authority's abuse, regarded as a provider of goods and services, contrary to the principle of religious freedom. It is concluded that the Consumer Protection Code (1990) is the main legislative source which through the faithful consumer can appeal to resolve conflicts related to the failure to provide promised religious services, the costly offering being an offense to religious freedom.

Keywords: Consumer law. Religious freedom. Religious consumption relationship. Loyal consumer vulnerability.

\section{SUMÁRIO}

1 Introdução. 2 A Liberdade Religiosa Como Princípio Estruturante da Sociedade Plural. 2.1 Categorização Estrutural do Princípio da Liberdade Religiosa. 3 A Cultura do Consumo e a Mercantilização do Sagrado. 3.1 A Atual Sociedade Consumista. 3.2 A Mercantilização do Sagrado, a Relação de Consumo Religiosa e a Consequente Aplicação do Código de Defesa do Consumidor. 4 Considerações Finais. 5 Referências. 


\section{INTRODUÇÃO}

A pluralidade concomitante de projetos de vida, além do individualismo, é uma das características da sociedade atual. Isso também reflete a profusão de religiões atualmente, ou seja, está em voga, no Ocidente, uma vez que a Era da Modernidade rompeu com a unidade de conceitos e pontos de vista, o princípio da liberdade religiosa.

Assim, não se fala mais em uma única religião, no caso a Católica Apostólica Romana, que dominou o cenário ocidental durante séculos, mas sim em um emaranhado de visões religiosas de mundo. Essa pluralidade religiosa reflete-se em vários rituais, aproximações com o sagrado, incluindo a oferta de bens com a promessa de prosperidade, salvação, destacando-se que muitas vezes esses bens são articulados com valores muito superiores aos de mercado, com a promessa de que estão sacralizados. ${ }^{1}$

Dessa forma, em função do relacionamento humano com o sagrado e tendo em vista o crescente número de consumidores lesados oriundo de problemas que o consumo religioso tem causado, o presente artigo analisa a polêmica da indústria cultural religiosa. Por indústria cultural religiosa entende-se o conjunto de interações no mercado de consumo destinadas à produção, reprodução e difusão de bens simbólicos de religião, aglutinando os mais diversos interesses mercadológicos, com a função de incutir no fiel-consumidor o desejo constante dos bens simbólicos oferecidos no mercado de consumo religioso, conforme Ivan de Oliveira Silva (2012).

Em um primeiro momento afirma-se que essa prática está inserida na gama de práticas pertinentes à religião, consubstanciando, desse modo, o exercício da liberdade religiosa. De outro lado, todavia, pode-se questionar como ofensa aos postulados do Direito do Consumidor quando da existência de algum abuso da autoridade religiosa, tida como fornecedora, contrariando o princípio da liberdade religiosa.

Nesse contexto surge a questão: $O$ direito fundamental à liberdade religiosa engloba as práticas decorrentes da oferta de produtos salvíficos, quais sejam, promessas de curas por intermédio de produtos sagrados, abençoados, itens que serão capazes de resolver problemas particulares em várias áreas (sentimental, financeira, de saúde)? Em resposta a esse questionamento, tem-se a necessidade da aplicação da Lei n. 8.078, de 1990 - Código de Defesa do Consumidor (CDC) - a tais relações, diante de excessos advindos dessa prática. Por conseguinte, faz-se necessário verificar os eventuais excessos decorrentes dessa prática, que não estão na matriz dos livros sagrados. Ademais, o Código de Defesa do Consumidor é a fonte legislativa por intermédio da qual o fiel-consumidor pode recorrer para solucionar conflitos relacionados à falha na prestação de serviços religiosos prometidos.

Assim, na seção intitulada: A liberdade religiosa como princípio estruturante da sociedade plural, aborda-se a estrutura da liberdade religiosa, analisando-se o seu desenvolvimento e limites. Na seção seguinte, com o título $A$ cultura do consumo e a mercantilização do sagrado, é analisada a questão do consumo do sagrado, ou seja, as promessas de cura e de sucesso por intermédio da aquisição de objetos materiais e a necessária proteção decorrente do Direito do Consumidor.

Este artigo mostra-se importante haja vista as situações de ofensa ao princípio da vulnerabilidade do consumidor diante do complexo de ofertas de salvação por intermédio da indústria cultural religiosa e sua relação com o princípio da liberdade religiosa, direito fundamental no Estado Democrático de Direito.

\section{A LIBERDADE RELIGIOSA COMO PRINCÍPIO ESTRUTURANTE DA SOCIEDADE PLURAL}

Remonta aos primórdios da humanidade a crença no sobrenatural, sendo possível perceber, ao longo da História, a influência da religiosidade na sociedade em vários aspectos, desde ritos que celebram o nascimento à influência na construção da moral social e da política na história de suas relações institucionais com o Estado.

Em relação à importância da religião nas sociedades humanas, Jónatas Eduardo Mendes Machado ressalta:

\footnotetext{
Em muitos casos é possível perceber que as instituições religiosas, inclusive, criaram centros para atendimento aos adquirentes dos produtos, ou seja, trata-se de um estruturado comércio.
} 
Os estudos arqueológicos, históricos e antropológicos colocaram em evidência o lugar central que a religião tem vindo a ocupar, desde sempre, nas sociedades humanas. Atualmente, esse fato é sublinhado pela sociologia. As formas de religiosidade são muito diversas entre si, embora seja possível encontrar semelhanças e pontos de contato em pelo menos muitas delas. Desde logo, a referência ao transcendente, ao sobrenatural, ao absoluto. Por força dessa sua natureza, ela é capaz de libertar energias incontroláveis, surgindo historicamente ligada ao que existe de melhor e de pior na história da humanidade (MACHADO, 1996, p. 9).

Em que pese a abertura ao transcendente, não se observam, durante os primórdios das sociedades humanas, as religiões institucionalizadas. "A religião era uma experiência da comunidade, necessariamente dissolvente do indivíduo" (MACHADO, 1996, p. 9). ${ }^{2}$ Posteriormente, o advento do cristianismo proporcionou um processo revolucionário nos âmbitos político e institucional, estruturando-se, num primeiro momento, "na afirmação dos direitos da Igreja em relação ao Estado (momento hierocrático), passando pela afirmação dos direitos do Estado em relação à Igreja (momento regalista) e colimando na afirmação dos direitos dos cidadãos relativamente a ambos (momento constitucional)" (MACHADO, 1996, p. 9-10).

Ainda quando não havia religiões institucionalizadas, a crença em algo que extrapolasse a condição humana era perceptível, tendo os primeiros povos deixado resquícios de desenhos retratando deuses, animais fantásticos. Por sua vez, com o desenvolvimento das instituições religiosas, a noção de religioso ultrapassou a condição individual para se relacionar com o fato de o crente ser uma pessoa vinculada a uma instituição religiosa. Desse modo, a visão de mundo religiosa não se confunde com as instituições religiosas, que surgiram num momento posterior da História. Em um segundo momento, tem-se a inter-relação entre Estado e religião, com o Estado oficializando um culto, para, em um momento posterior, desenvolverem-se instituições religiosas, com dogmas, rituais.

No Ocidente, a instituição religiosa dominante, durante vários séculos, foi a Igreja Católica Apostólica Romana, principalmente após as invasões bárbaras, as quais romperam as bases organizacionais dos Estados europeus de então. A Igreja, no entanto, em decorrência de vários fatores, entre eles sua organização, manteve fortalecido seu poder durante a Idade Média. Essa situação, contudo, sofre alteração com a Reforma Protestante (século 16), quando então há a percepção de outros olhares religiosos, desencadeando o protestantismo, o que, a partir de então, foi fundamental para o desenvolvimento do princípio da liberdade religiosa, haja vista o rompimento da unidade religiosa institucional ocidental.

O princípio da liberdade religiosa está na gênese dos direitos humanos, como ressaltou Georg Jellinek (2000), sendo própria do Estado Democrático de Direito, um sistema democrático real, que se desenvolve numa linha de suporte democrática e pluralista.

Na próxima subseção analisa-se a estrutura do princípio da liberdade religiosa, sem se descurar de um resumo sobre o seu desenvolvimento na História ocidental.

\subsection{Categorização Estrutural do Princípio da Liberdade Religiosa}

Até o Edito de Milão (313), o cristianismo era uma religião perseguida, tornando-se posteriormente uma religião autorizada, para, enfim, tornar-se a religião oficial do Estado Romano, o que ocorreu no ano de 380, sob o pálio do imperador Teodósio, substituindo a religião romana estatal. "Isto significava que, agora, o Deus cristão era o fiador da ordem estatal, com todas as consequências daí decorrentes. Dito de maneira mais clara: a unidade religiosa era fundamento da unidade política" (BABIĆ, 2016, p. 14).

Observa-se, desse modo, que, qualquer ofensa contra a religião caracterizava, consequentemente, uma ofensa contra o Estado. Com Constantino, o Grande, o cristianismo desenvolveu-se no Ocidente sob a soberania do Estado. ${ }^{3}$ Posteriormente, com a divisão do Império Romano em oriental e ocidental, consumada no ano

\footnotetext{
Desde que o ser humano se entende como tal, começou a fazer para si imagens, mais ou menos elaboradas, representando a realidade. "Através dessas imagens interpretava as suas próprias experiências e tentava descobrir-lhes um sentido ordenador, que reproduzia através de um modelo discursivo" (MACHADO, 1996, p. 14). Observa-se, assim, uma relação muito íntima entre sagrado e profano, não sendo possível separar a vida religiosa da vida em comunidade.

3 Mile Babić observa: "o imperador (que é um leigo) é mais íntimo de Deus do que qualquer bispo. Ele é o lugar-tenente de Deus sobre a terra. Ele tem o poder e a obrigação de submeter todas as pessoas à justa lei de Deus, e esta, agora, é o Cristianismo, em vez a religião romana. Constantino era o portador da potestas suprema, do primado da jurisdição perante a Igreja; ele detinha o mais alto poder legislador, o mais elevado poder judicial e o controle administrativo" (BABIĆ, 2016, p. 15).
} 
de 395 da Era Cristã, houve o desenvolvimento de vários paradigmas na Teologia e na política no Ocidente, como também no Oriente. No Ocidente a política foi determinada pelos papas romanos dos séculos 4ㅇ e 5o, situação que conduziu à supremacia da Igreja sobre o Estado. Assim, Mile Babić ressalta que:

\begin{abstract}
A fim de compreender o paradigma teológico ocidental, devem-se levar em consideração as migrações dos povos germânicos nos séculos $\mathrm{V}$ e VI e o ocaso do Império Romano ocidental em 476, o batismo do rei franco Clóvis em 498/99, o aparecimento do Islã, bem como o surgimento do império cristão sob Carlos, o Grande. $O$ paradigma ocidental, católico-romano viveu seu ápice durante a reforma (ou revolução) gregoriana no final do século XI (BABIĆ, 2016, p. 14).
\end{abstract}

Com as invasões bárbaras na Idade Média, o panorama de influência da Igreja Católica como moduladora do poder político ficou ainda mais nítido e sólido, em decorrência do esfacelamento das organizações estatais antigas. Em 751, Pepino, o Breve (741-768), recebeu, como primeiro rei franco, a unção, tornando-se Rei da Graça de Deus (Gratia Dei Rex), ou seja, o seu poder era divinamente legitimado.

A partir daí a História mostra um ambiente caracterizado pela supremacia da Igreja Católica durante séculos, inexistindo o princípio da liberdade religiosa, haja vista a existência de uma única religião institucionalizada. Essa situação sofre modificação com a Reforma Protestante do século 16, ocasião em que as bases de um novo olhar religioso institucional são desencadeadas. Assim, não há que se falar mais em somente uma religião, haja vista o desenvolvimento do protestantismo, dele decorrendo várias vertentes na Europa. É nesse momento histórico que se tem, por conseguinte, o gérmen do princípio da liberdade religiosa.

A liberdade religiosa é gênero, do qual se desdobram as seguintes liberdades: $i$ ) liberdade de consciência, ii) liberdade de crença, iii) liberdade de culto e iv) liberdade de organização, conforme ressalta Márcio Eduardo Senra Nogueira Pedrosa Morais (2015). Nesse sentido, a liberdade de crença garante ao sujeito o direito de escolher entre qualquer religião, qualquer crença. A liberdade de culto representa a exteriorização popular da liberdade de crença, a manifestação física mediante rito ou solenidade. A liberdade de organização, por sua vez, refere-se à possibilidade de estabelecimento e organização de igrejas e suas relações com o Estado.

Esmiuçando os dois termos, liberdade e religião, com o intuito de apresentar um conceito, tem-se como necessário identificá-los. Assim, conforme pontua Ronald Dworkin, entende-se como religião "uma cosmovisão profunda e abrangente, dotada de características distintas: sustenta que todas as coisas são permeadas de um valor intrínseco e objetivo, que o universo e suas criaturas inspiram admiração, que a vida humana tem um propósito e o universo, uma ordem" (DWORKIN, 2019, p. 3).

O núcleo metafísico da religião sustenta que a vida humana tem um sentido ou uma importância objetiva. Desse modo, "cada pessoa tem a responsabilidade inata e inescapável de tentar fazer com que sua vida seja bem-sucedida, ou seja, de viver bem, aceitando suas responsabilidades éticas para consigo mesma e suas responsabilidades morais para com os outros" (DWORKIN, 2019, p. 11). Ademais, sustenta-se que, "aquilo que se chama de natureza, o universo como um todo e em cada uma de suas partes - não é uma simples questão de fato, mas algo sublime em si mesmo" (2019, p. 11).

Decompondo o conceito de religião, sustentado no referencial teórico dworkiano, tem-se a religião como a atitude que i) entende possuir, a vida humana, um sentido objetivo, qual seja, fazer com que a vida seja bem-sucedida no que se refere a compromissos éticos; ii) entende a natureza (o universo) como um todo, dotado de valor e maravilhamento intrínsecos.

No que se refere ao termo "liberdade", Brian H. Bix (2009) salienta ser este compreendido como ausência de limitações à ação, em especial à falta de limitações jurídicas.

Conforme ressaltam Norberto Bobbio, Nicola Matteucci e Gianfranco Pasquino, a palavra "liberdade"

[...] tem uma notável conotação laudatória. Por esta razão, tem sido usada para acobertar qualquer tipo de ação, política ou instituição considerada como portadora de algum valor, desde a obediência ao direito natural ou positivo até a prosperidade econômica (1998, p. 708).

Fato é que o conceito jurídico de liberdade é aberto, comportando vários significados. Não seria equivocado afirmar que a melhor conceituação seria a filosófica. Dessa forma, o conceito filosófico de liberdade possui, de acordo com Nicola Abbagnano, 
[...] três significados fundamentais, correspondentes a três concepções que se sobrepuseram ao longo de sua história e que podem ser caracterizadas da seguinte maneira: 1 Liberdade como autodeterminação ou autocausalidade, segundo a qual a liberdade é ausência de condições e de limites; 2 Liberdade como necessidade, que se baseia no mesmo conceito da precedente, a autodeterminação, mas atribuindo-a à totalidade a que o homem pertence (Mundo, Substância, Estado); 3 Liberdade como possibilidade ou escolha, segundo a qual a liberdade é limitada e condicionada, isto é, finita (1998, p. 605-606).

De acordo com a primeira concepção, transmitida na Antiguidade e durante toda a Idade Média, liberdade consistia não somente em ter em si a causa dos próprios movimentos, como também em ser essa causa. Essa concepção privilegia os seres humanos, tendo em vista ser a causa dos movimentos aquilo que o próprio homem escolhe como móbil, na condição de árbitro e juiz das circunstâncias externas, conforme Abbagnano (1998).

Luiz Pinto Ferreira conceitua liberdade religiosa como "o direito que tem o homem de adorar a seu Deus, de acordo com a sua crença e o seu culto" (1998, p. 102). Sob um conceito mais detalhado, Jorge Miranda (2000) ressalta que:

A liberdade religiosa não consiste apenas em o Estado a ninguém impor qualquer religião ou a ninguém impedir de professar determinada crença. Consiste ainda, por um lado, em o Estado permitir ou propiciar a quem seguir determinada religião o cumprimento dos deveres que dela decorrem (em matéria de culto, de família ou de ensino, por exemplo) em termos razoáveis. E consiste, por outro lado (e sem que haja qualquer contradição), em o Estado não impor ou não garantir com as leis o cumprimento desses deveres (p. 409).

Fato é que a liberdade religiosa, como direito fundamental, é gênero que comporta espécies, entre elas: a liberdade de crença, a liberdade de culto e a liberdade de organização religiosa, conforme já destacado.

Desse modo, a liberdade religiosa garante ao sujeito o direito de escolha entre qualquer religião, ou seja, aquela que melhor the convier, constituindo, assim, o direito de escolher entre crenças, nos aspectos positivo e negativo, ou seja, crer ou não crer. Em resumo: a liberdade de crença é o direito de crer ou não crer em uma divindade. Por sua vez, a liberdade de organização religiosa diz respeito à possibilidade de estabelecimento e organização de Igrejas e suas relações com o Estado.

A liberdade religiosa situa-se no discurso jurídico-constitucional tendo como premissa o valor da igual dignidade e liberdade de todos os cidadãos, procurando apresentar um conceito de religião e de liberdade religiosa dotado de um grau de inclusividade compativel com aquele valor, que afaste dos domínios das opções de fé e da vivência religiosa qualquer forma de coerção e discriminação jurídica ou social, de acordo com Machado (1996). Desse modo, para que tais objetivos sejam alcançados, faz-se fundamental a separação das confissões religiosas do Estado.

Historicamente, pode-se situar a Constituição dos Estados Unidos da América de $1787^{4}$ como o marco da positivação do princípio da liberdade religiosa, estando o referido princípio situado especificamente na sua primeira emenda, com o seguinte enunciado:

EMENDA I - O Congresso não legislará no sentido de estabelecer uma religião, ou proibindo o livre exercício dos cultos; ou cerceando a liberdade de palavra, ou de imprensa, ou o direito do povo de se reunir pacificamente, e de dirigir ao governo petições para a reparação de seus agravos (ESTADOS..., 2019).

Da análise dessa primeira emenda depreendem-se duas cláusulas: a primeira, denominada establishment clause, que separa as confissões religiosas do Estado. De acordo com essa cláusula, o Congresso norte-americano está impedido de legislar com o objetivo de se estabelecer uma religião oficial nos Estados Unidos. Por sua vez, a segunda cláusula, free exercise clause, garante o direito à liberdade religiosa, permitindo o livre exercício dos cultos.

Posteriormente, em 1789, com a Declaração de Direitos do Homem e do Cidadão da Revolução Francesa, é novamente garantido o direito à liberdade religiosa. Nesse sentido, a Declaração previa em seu artigo 10응 que "ninguém pode ser molestado por suas opiniões, incluindo opiniões religiosas, desde que sua manifesta-

\footnotetext{
${ }_{4}$ Em 1620 chega à então Nova Inglaterra o Mayflower, trazendo imigrantes que foram buscar na América do Norte um local onde houvesse liberdade religiosa. Esses imigrantes fugiram da intolerância religiosa das monarquias europeias, católicas e protestantes.
} 
ção não perturbe a ordem pública estabelecida pela lei" (FRANÇA, 2019). Como marco inspirador do Direito ocidental, a Declaração de 1789 previa a proibição de se molestar alguém por motivo de opiniões religiosas, salientando-se que, desde que tal manifestação não perturbasse a ordem pública, ou seja, como é acorde na doutrina e jurisprudência: nenhum direito fundamental é absoluto, e no texto de 1789 havia já tal concepção de relatividade.

É fundamental salientar que compete ao Estado garantir o respeito às opções de ateus e agnósticos, tendo em vista serem eles muitas vezes confundidos com pessoas ligadas a rituais macabros, diabólicos, adoradores de demônios, sendo muitas vezes também perseguidos, principalmente em se tratando de uma sociedade com religiosidade marcante como a brasileira. Assim, é fundamental a existência de leis garantindo-lhes a igualdade de crenças (MORAIS, 2011).

Sob o discurso da religião está desenvolvido um comércio de bens (por parte de algumas instituições religiosas) com a promessa de cura, salvação, desenvolvimento econômico e profissional. Há venda pela televisão, pela Internet, os preços são mais altos do que o normal, muitas vezes com valores que remetem a números simbólicos.

Assim, abordado o princípio da liberdade religiosa, passa-se, na próxima seção, à análise dessa mercantilização, à luz do referido princípio e da legislação consumerista brasileira.

\section{A CULTURA DO CONSUMO E A MERCANTILIZAÇÃO DO SAGRADO}

Atualmente $o$ ato de consumir é formador de identidade individual e coletiva, criando-se uma cultura em que o consumo sequer se restringe à satisfação de necessidades ou desejos, para dar causa à formação de um comportamento comum, cujo desvio acarreta inadequação e exclusão do indivíduo de um determinado círculo de relações. Impõe-se ao consumidor "globalizado" um modelo de consumo predatório, a precarização de suas relações pessoais autênticas e a terceirização de suas escolhas aos ditames da indústria cultural. 0 consumo compulsivo tornou-se o remédio necessário para aplacar as carências pessoais e profissionais do indivíduo, o que se agrava pela exigência social da difícil conciliação entre o sucesso pessoal e profissional, algo vendido pela mídia como o desafio do consumidor hipermoderno.

Há, na atualidade, segundo Michael R. Solomon (2016), um realinhamento hierárquico da necessidade de consumo, outrora marcada por condições fisiológicas, hoje determinadas pelo padrão estético-comportamental da indústria cultural e difundida pelo assédio modificado. A pirâmide de Maslow traz: 1:: autorrealização (ex. hobbies e educação); 2ㅇ: egocentrismo (status, ex. cartões de crédito); 3:: pertencimento (aceitação, ex. vestuário); 4ㅇ: segurança e 5ㅇ: fisiologia (remédios, alimentos). 0 consumo, como remédio e terapia, tem um custo variável em relação ao grau de vulnerabilidade do consumidor. Reconhecida a vulnerabilidade psicológica e comportamental, é certo que pagará mais caro por a) sua realização; b) seu egocentrismo; c) seu pertencimento; d) sua segurança.

A globalização disseminou uma cultura em que toda a estrutura social passou a ser articulada para o consumo. Na busca de localizar-se e preencher os seus temores provocados pelas tensões da vida moderna, resta ao ser humano apelar, segundo propõe o mercado capitalista, para o consumo. 0 discurso publicitário segue no sentido de que falta alguma coisa, assim como as propagandas (merchandising) passaram a ser cada vez mais apelativas para atrair mais consumidores. ${ }^{5}$

Pode-se afirmar que a proteção do consumidor é consequência das modificações havidas nos últimos tempos nas relações consumeristas, representando a reação ao avanço rápido do fenômeno, que deixou o consumidor desprotegido ante as novas situações decorrentes do desenvolvimento. O reconhecimento de que o consumidor estava desprotegido em termos educacionais, informativos, materiais e legislativos determinou maior atenção para o problema e o aparecimento de legislação protetiva em vários países.

\footnotetext{
O comércio passou a estimular datas comemorativas, como exemplo da criação da Black Friday (termo criado pelo varejo norte-americano para nomear a ação de vendas anual que ocorre sempre na última sexta-feira de novembro, após o feriado de Ação de Graças) nos Estados Unidos. A Black Friday chegou ao Brasil em 2010 por iniciativa de uma empresa especializada em busca de descontos - para incentivar a compra de presentes e também houve facilitação no crédito. O consumo passou a ser considerado um ato de autoafirmação social.
} 
As profundas modificações das relações de consumo, a identificação dos interesses difusos e coletivos, a nova postura em relação à legitimação ativa e o reconhecimento da vulnerabilidade do consumidor contribuíram para o surgimento de tutela respectiva. Com o objetivo de regular e estabelecer o equilíbrio buscou-se criar uma norma regulamentadora, caminhando assim para a criação do Código de Defesa do Consumidor. Tornou-se possível concluir que o CDC é o instrumento legal de realização dos valores constitucionais de proteção e defesa dos consumidores, tais como a saúde, a segurança, a vulnerabilidade, entre outros. Ou seja, destina-se a efetivar no plano infraconstitucional princípios constitucionais, especialmente os princípios da isonomia substancial e da defesa do consumidor.

\subsection{A Atual Sociedade Consumista}

A sociedade, com fortes propensões ao consumismo, encontra-se vinculada ao atual sistema econômico, identificado como capitalismo de consumo. Atualmente o exemplo mais marcante da manifestação da cultura de consumo é o shopping center, além dos hipermercados nos quais tudo é demonstrado a partir da ideia de abundância. São espaços que dão ao consumidor uma sensação espetacular da vida, onde vale a pena até mesmo a demora para encontrar uma vaga no estacionamento, eis que o incômodo pode ser contabilizado como pequenos sacrifícios a serem recompensados pela experiência do consumo oferecido na estrutura do ambiente de compras.

Segundo Ivan de Oliveira Silva (2012), nas sociedades promotoras da cultura de consumo o ato de consumir, às vezes, mostra-se como um milagre, tendo como exemplo o "milagre" de comprar sem dinheiro, por meio do financiamento. Desse modo, as relações de consumo passaram a ser comuns no cotidiano de qualquer ser humano, independentemente de classe social, nas tarefas mais simples do dia a dia. Toda relação de consumo é bilateral, ou seja, consumidor e fornecedor, este previsto no artigo 3으 do CDC e que pode tomar a forma de fabricante, produtor, importador, comerciante e prestador de serviço, ou seja, aquele que se dispõe a fornecer bens e serviços a terceiros, e aquele disposto no artigo 20 do mesmo Código, que é subordinado às condições e aos interesses impostos pelo titular dos bens ou serviços.

A capacidade de consumo pode ser esticada muito além dos limites estabelecidos por quaisquer necessidades naturais ou adquiridas; a durabilidade física dos objetos do desejo também não é mais exigida. Conforme Bauman (1999), a relação tradicional entre necessidades e sua satisfação é revertida: a promessa e a esperança de satisfação precedem a necessidade que se promete satisfazer e serão sempre mais intensas e atraentes que as necessidades efetivas.

O comportamento do consumidor vem sofrendo influência da indústria cultural, patrocinada por um mercado que fideliza o consumidor forjando a necessidade de consumo. A ideia de felicidade imediata tornou-se objeto explícito de consumo numa sociedade doente e induzida a frustrações e carências. Em outras palavras, além da felicidade paradoxal que o consumo pode proporcionar, há que se considerar, também, uma felicidade artificial industrializada e que deve ser sentida instantaneamente por meio de "pílulas mágicas", vendidas como adereço fundamental para a solução rápida de problemas complexos.

A ilusão consumista pauta-se na substituição da verdade por uma impostura. O consumismo despreza a simplicidade dos modos naturais de impressionar e mostrar um valor intrínseco, a partir de duas falácias: a) produtos acima da média podem compensar características abaixo da média, quando a intenção é construir relacionamentos sérios (exemplo: cirurgias estéticas); b) alguns produtos objetivam simbolizar status social (exemplo: carro de luxo e vestuário). Há, portanto, um permanente conflito entre os bens de consumo e os comportamentos humanos, estando assim o consumidor em posição de fragilidade alimentada pelo próprio mercado que lucra com o assédio para um consumo compulsivo.

O mercado de consumo seduz os consumidores. Numa sociedade de consumo que funcione de forma adequada os consumidores buscam com todo empenho serem seduzidos. É essa combinação dos consumidores ávidos por novas atrações e logo enfastiados com atrações já obtidas, e de um mundo transformado em todas as suas dimensões - econômicas, políticas e pessoais - segundo o padrão do mercado de consumo, e o mercado, pronto a agradar e mudar suas atrações com uma velocidade cada vez maior; é essa combinação que varre toda sinalização fixa dos mapas individuais do mundo e dos projetos itinerários de vida. 


\subsection{A Mercantilização do Sagrado, a Relação de Consumo Religiosa e a Consequente Aplicação do Código de Defesa do Consumidor}

Como observado na subseção anterior, é próprio da sociedade consumista a promessa da felicidade por intermédio do consumo. Diante disso, é possível perceber a promessa da salvação, situação comum desde tempos antigos, por meio das práticas das indulgências por parte da Igreja Católica. O princípio da liberdade religiosa desenvolve-se por intermédio da Reforma Protestante, em decorrência dos novos olhares religiosos desenvolvidos a partir de então. Desse modo, houve a quebra do monopólio religioso da Igreja Católica, o que contribuiu, ainda, para o aumento das instâncias promotoras do sagrado.

Conforme destaca Ivan de Oliveira Silva, esse fato estabeleceu uma realidade competitiva entre as diversas organizações religiosas:

A competição está atrelada à formação do maior número de seguidores. Nesse contexto, a instância promotora do sagrado passa a se preocupar em agradar o fiel-consumidor, sob pena de perdê-lo para o concorrente que apresentar ambientes e práticas litúrgicas mais agradáveis aos seus interesses (SILVA, 2019).

Essa realidade gerou a concorrência entre as instâncias promotoras do sagrado, dentro da religião de mercado, na tentativa de se aumentar os espaços para ampliação dos bens simbólicos da religião. Diante dessa concorrência, é necessário frisar que se trata de uma relação de consumo religiosa, que deve ser tutelada pelos dispositivos legais pertinentes, em especial pelo Código de Defesa do Consumidor.

Com uma linguagem de salvação, articulada para que seja atraído o maior número possível de fiéis-consumidores, há ofertas de bens materiais de várias espécies. Os fatos compulsados na Internet mostram ofertas de bens materiais com valores muito acima da média. Em alguns casos, representantes de igrejas ${ }^{6}$ oferecem água ungida, fronhas abençoadas, meias, colheres de pedreiro, canetas.

Em todos os casos, os líderes religiosos ressaltam tratar-se de bens sagrados, que transformarão a vida dos adquirentes, resolvendo pendências judiciais, amorosas, financeiras, de saúde. Logo em seguida à oferta dos produtos os fiéis são convidados a prestarem seus depoimentos pessoais afirmando terem adquirido os produtos e resolvido problemas. Essa relação enquadra-se nos dispositivos dos artigos 2ㅇ e 3음 do CDC, eis que de um lado há um profissional comercializando um produto e de outro um consumidor que o adquire na condição de destinatário final.

Há a formação de um preocupante cenário em que a liberdade de escolha do consumidor é violada, na medida em que seu potencial crítico é muitas vezes nulificado em prol de pseudonecessidades estabelecidas pela atuação midiática da indústria cultural religiosa, seja por meio da publicidade, seja por mensagens subliminares, apenas para garantir a supressão de qualquer escolha contrária aos padrões impostos.

O fiel-consumidor é colocado em uma situação em que se vê constrangido e pressionado a adquirir os bens considerados necessários. Desse modo, tem-se no caso concreto a vulnerabilidade do consumidor. 0 princípio da vulnerabilidade é a espinha dorsal da proteção do consumidor, conforme ressalta João Batista de Almeida (2000), sobre a qual se assenta toda a filosofia do movimento consumerista.

A vulnerabilidade consiste na necessidade de o Direito passar a tutelar positivamente aquele que se encontra em uma situação de fraqueza ante a relação jurídica, visando a equilibrar a disparidade de forças nela verificada e deve ser entendida como corolário do princípio da igualdade material. Tradicionalmente, tem sido subdividida de acordo com os seguintes aspectos: técnica, científica, fática e informacional.

A vulnerabilidade técnica expressa-se pelo menor conhecimento do consumidor em relação ao fornecedor sobre as características dos produtos ou serviços adquiridos. Por conta dela o consumidor fica à mercê das informações prestadas pelos fornecedores acerca de seus produtos e serviços. A vulnerabilidade jurídica ou científica retrata a presunção de que o consumidor apresenta um conhecimento limitado ou inexistente sobre questões jurídicas, contábeis e econômicas, sobretudo diante das relações contratuais massificadas, normalmente travadas por meio de contratos de adesão. Como bem destacam Cláudia Lima Marques e Bruno Miragem (2014), essa forma de vulnerabilidade é característica dos contratos de empréstimo bancário e finan-

É utilizado o termo igreja para se referir, de maneira geral, às instituições religiosas. 
ciamento, em que a complexidade das cláusulas contratuais, que englobam questões atinentes a juros, formas de dedução das parcelas, multas, entre outros assuntos, dificulta o entendimento do consumidor, podendo levá-lo a se vincular a um contrato efetivamente não satisfatório para o seu melhor interesse, muitas vezes até mesmo lesivo.

A vulnerabilidade fática ou socioeconômica manifesta-se pela disparidade existente entre o consumidor e o fornecedor, marcada pela fragilidade do primeiro em contraste com o maior poderio econômico do segundo. Os contratos de adesão ilustram essa forma de vulnerabilidade, pois impedem qualquer tentativa de negociação das cláusulas. Quanto à vulnerabilidade informacional, se o consumidor sofre, naturalmente, com um déficit de informação em relação ao fornecedor, paradoxalmente, com o desenvolvimento contínuo dos meios de comunicação, com destaque para a Internet e as redes sociais, é preciso reconhecer que as pessoas nunca tiveram tanto acesso à informação como ocorre atualmente. Como, no entanto, apontam Cláudia Lima Marques e Bruno Miragem (2014), além de abundante, a informação também é manipulada, controlada e, quando fornecida, no mais das vezes, desnecessária.

São justamente essas características que evocam a necessidade de consideração da existência da vulnerabilidade informacional, cujo reconhecimento encontra respaldo no princípio da dignidade da pessoa humana. A questão da informação tornou-se tão complexa em nossa sociedade de consumo que se fala na existência de uma hipervulnerabilidade do consumidor, que, apesar de ser constantemente informado pelos fornecedores, principalmente por meio de campanhas publicitárias, muitas vezes acaba sendo manipulado pelo parceiro contratual.

É possível ainda destacar a vulnerabilidade comportamental do consumidor da qual tratam Dennis Verbicaro, Lays Rodrigues e Camille Ataíde (2018), apresentada como característica latente do atual estágio da sociedade de consumo. Há que se considerar um fator determinante no reconhecimento da vulnerabilidade comportamental diante do assédio de consumo: o risco percebido. Decorre de duas premissas: a) o consumidor acredita que pode haver consequências negativas se escolher a opção errada; b) quando a escolha é visível para outras pessoas, o consumidor tem uma predisposição maior ao constrangimento se fizer a escolha errada e eventualmente sofrer rejeição de seus pares, ou mesmo superestimar o grau de relevância que os demais atribuem a um determinado símbolo de consumo.

Da mesma forma que os consumidores dos produtos e serviços não religiosos são vulneráveis, os consumidores dos bens de religião também encontram-se em condição de vulnerabilidade, haja vista a condição de leigos em que se apresentam nas suas relações com as instâncias promotoras do sagrado. Além da vulnerabilidade socioeconômica e técnica também se observa a vulnerabilidade teológica do consumidor, que não compreende exatamente os termos e teses inerentes ao campo da Teologia, sendo, ainda, pressionado pelo discurso do poder religioso, que é dotado de fortes componentes psicológicos.

No que se refere à relação de consumo religiosa, os elementos são específicos, diante da relação de consumo genérica, em que são elementos os sujeitos e o objeto, respectivamente, consumidor e fornecedor de produtos e serviços. Nos termos do artigo 2ㅇ do Código de Defesa do Consumidor, "consumidor é toda pessoa física ou jurídica que adquire ou utiliza produto ou serviço como destinatário final" (BRASIL, 2019). São objetos da relação de consumo os produtos ou serviço e a contraprestação. $E$, ainda, equipara-se a consumidor a coletividade de pessoas, ainda que indetermináveis, que interfira nas relações de consumo. Consumidor, portanto, pode ser pessoa física ou pessoa jurídica que adquirir produto ou serviço como destinatário final, seja a título oneroso ou gratuito.

O CDC estabeleceu três definições de consumidor equiparado. São os casos do artigo 2ำ, parágrafo único, artigo 17 e artigo 29 do CDC: o que se percebe é a desnecessidade da existência de um ato de consumo, bastando, para a incidência da norma, que esteja o sujeito exposto às situações previstas no Código, seja na condição de integrante de uma coletividade de pessoas, como vítima de um acidente de consumo ou como destinatário de práticas comerciais, e de formação e execução do contrato previsto no artigo 29. Já o conceito de fornecedor encontra previsão no artigo 3ำ, que dispõe que fornecedor é toda pessoa física ou jurídica, pública ou privada, nacional ou estrangeira, bem como os entes despersonalizados, que desenvolvem atividade de produção, montagem, criação, construção, transformação, importação, exportação, distribuição ou comercialização de produtos ou prestação de serviços (BRASIL, 2019). 
Nas relações de consumo, o sujeito vulnerável é inequivocamente o consumidor, uma vez que, não detendo os mecanismos de controle do processo produtivo, e dele participando apenas em sua última etapa, pode ser ofendido, em sua integridade física, econômica, psicológica ou moral. Já no mercado de consumo religioso identifica-se a presença dos seguintes sujeitos: o consumidor na pessoa do fiel-consumidor, em busca de bens simbólicos de religião para a satisfação de seus interesses e as instâncias promotoras do sagrado que, na condição de fornecedores, procuram aquecer o mercado de consumo religioso com o manejo de seu capital simbólico (CAVALIERI FILHO, 2010).

Na relação entre aqueles denominados por Ivan de Oliveira Silva (2012), fiel-consumidor e instâncias promotoras do sagrado, aplica-se o CDC, eis que, numa visão atenta, verifica-se a presença dos elementos de incidência da referida norma, quais sejam: $i$ ) o fiel-consumidor: sujeito que se manifesta como um consumidor qualificado que está ou poderá estar interessado na aquisição de produtos e/ou serviços de conotação religiosa. A partir disso, seguindo a estrutura do $\mathrm{CDC}$, há também a figura dos fiéis-consumidores equiparados, conforme segue: o fiel-consumidor enquanto coletividade de pessoas (artigo 2ㅇ, parágrafo único); o fiel-consumidor vítima de acidente de consumo (artigo 17) e o fiel-consumidor exposto às peças publicitárias e demais práticas religiosas (artigo 29); ii) as instâncias promotoras do sagrado: organizações ou organismos religiosos, detentores do capital simbólico religioso, responsáveis pela criação, reprodução e difusão de bens simbólicos de religião no campo religioso brasileiro e iii) os bens simbólicos de religião: expressão utilizada para contemplar produto e serviço religioso. Todos fazem parte do capital simbólico das instâncias promotoras do sagrado. São eles elementos sacralizados, tangíveis (por exemplo: uma toalha ungida com o suor do representante do sagrado) ou intangíveis (por exemplo: uma oração forte), oferecidos no mercado de consumo religioso.

O objeto da relação jurídica de consumo é o elemento motivador da aproximação entre o consumidor e o fornecedor: produtos e/ou serviços. Na relação de consumo religiosa são identificados como bens simbólicos de religião os produtos e serviços religiosos capazes de permitir pontos de contato com o sagrado. São eles bens corriqueiros que, por atos litúrgicos diversos, recebem atributos ou qualidades especiais que os identificam com o sagrado. Consoante a constituição da relação de consumo religiosa estabelecida no campo religioso contemporâneo, o instrumento legislativo pertinente à defesa dos interesses do fiel-consumidor é o Código de Defesa do Consumidor.

Nos conflitos relacionados ao campo religioso, a jurisprudência tem aplicado o Código Civil, um diploma concebido para regulamentar as relações jurídicas entre iguais. É possível concluir, porém, que essa prática jurisprudencial está equivocada, eis que nos confrontos judiciais entre aqueles denominados fiéis-consumidores e as instâncias promotoras do sagrado, o estatuto legislativo adequado é o CDC, uma vez que essa relação se enquadra no seu cabedal normativo. Ele sim mostra-se hábil para regulamentar as relações jurídicas entre pessoas em condição de desigualdade que, de maneiras diversas, se encontram no mercado de consumo.

Em síntese, a tese de aplicação do CDC às relações de oferta de bens sagrados sustenta-se nas seguintes ponderações: $i)$ o CDC foi concebido para incidência em todas as dimensões do mercado de consumo, por mais especializadas e complexas que possam elas se apresentar; ii) foi constituído um mercado de consumo especializado, o religioso, fartamente explorado pela indústria cultural religiosa, que, por sua vez, apresenta-se como um instrumento destinado a atrair o fiel-consumidor; iii) há, no mercado de consumo religioso, um fiel-consumidor vulnerável que carece de proteção diante das práticas mercadológicas das instâncias promotoras do sagrado alicerçadas sob a ótica de oferta e de procura de bens simbólicos de religião; iv) os elementos constitutivos da relação de consumo religiosa não são excluídos da noção de relação de consumo apresentada pelo CDC.

\section{CONSIDERAÇÕES FINAIS}

O estudo delineou o processo de criação da cultura de consumo contemporânea, em que as massas, motivadas pela razão instrumental, organizam suas ações em torno do consumo. $O$ ato de consumo tornou-se a razão última da existência e, por conta disso, o consumismo manifesta-se de maneira global nos países que adotaram o regime econômico do capitalismo de consumo. 
Vivencia-se, atualmente, um período em que o consumismo se difunde, naturalmente, pelas várias instâncias e instituições sociais. O modo de vida contemporâneo gira, para um conjunto difuso de pessoas, em torno do consumo, seja de produtos e serviços elementares à manutenção da vida humana, seja o consumo de produtos e serviços destinados à mera satisfação de pretensões supérfluas. É o que se pode identificar como consumo utilitário, que não leva em conta as consequências do ato de consumo.

O consumo transformou-se em uma sequência de manifestações destinadas à exteriorização do gosto, à reivindicação de status social, bem como cenário ao espetáculo do excesso. Nada escapa ao desejo de consumo. Em decorrência da disseminação da cultura do consumo que abrange um número significativo de indivíduos, as massas são manipuladas pelo mercado, visto que o próprio desejo de consumir é fabricado pela técnica mercadológica.

Observou-se que no campo religioso há uma indústria cultural especializada, denominada indústria cultural religiosa. O seu papel centra-se na reunião de esforços destinados a despertar, nesse campo, o desejo nas massas pela aquisição de produtos e serviços religiosos. O sagrado tornou-se objeto de desejo no mercado de consumo e, por conta disso, é ele amplamente mercantilizado no mercado religioso por meio da oferta dos bens simbólicos de religião.

Trata-se de um mercado amplamente competitivo, com oferta intensa de bens simbólicos de religião, ocasionando a demanda mercadológica de oferta e procura do sagrado no mercado de consumo, passando a haver a figura do fiel-consumidor, o consumidor de produtos e serviços religiosos, que padece de vulnerabilidade diante dos fornecedores de bens de religião (instâncias promotoras do sagrado).

Nesse sentido, entende-se que o campo religioso brasileiro, influenciado pelas leis de mercado, apresenta a constituição de relações de consumo em que o fiel-consumidor e a instância promotora do sagrado negociam produtos e serviços religiosos carregados com a simbologia do sagrado. Diante da relação de consumo firmada no campo religioso, abre-se espaço para a expressão relação de consumo religiosa, que deverá ser regulamentada pelo Código de Defesa do Consumidor, amparado pelo fato de que as definições de consumidor, fornecedor, produtos e serviços presentes no referido Código não excluem as categorias identificadas no campo religioso brasileiro.

Considerando, ainda, a manifesta mercantilização do sagrado, sob o fomento da indústria cultural religiosa, bem como a vulnerabilidade do consumidor de bens de religião, defende-se que o Código de Defesa do Consumidor é o instrumento hábil para a defesa do fiel-consumidor no mercado de consumo especializado em bens simbólicos de religião.

Desse modo, as práticas decorrentes da oferta de produtos salvíficos não decorrem do princípio da liberdade religiosa, caracterizando relação de consumo a qual, por conseguinte, deve respeitar os postulados do Código de Defesa do Consumidor.

Ademais, as práticas efetivadas por algumas instituições religiosas, principalmente evangélicas, contrariam, inclusive, um dos postulados basilares da Reforma Protestante, qual seja, a venda de indulgências e simonias, ou seja, o perdão e o privilégio de se utilizar ou possuir um objeto sagrado mediante pagamento.

\section{REFERÊNCIAS}

ABBAGNANO, Nicola. Dicionário de filosofia. São Paulo: Martins Fontes, 1998.

ALMEIDA, João Batista de. A proteção jurídica do consumidor. 2. ed. São Paulo: Revista dos Tribunais, 2000.

ANDRADE, José Carlos Vieira de. Os direitos fundamentais na constituição portuguesa de 1976. Coimbra: Almedina, 1987.

ARAÚJO, João Victor Nogueira de. Aplicação do Código de Defesa do Consumidor às relações comerciais religiosas. Revista Jus Navigandi, Teresina, ano 23, n. 5.359, 4 mar. 2018. Disponível em: https://jus.com.br/artigos/63943. Acesso em: 16 maio 2019.

BABIĆ, Mile. O cristianismo: da religião estatal para a liberdade de religião. Concilium - Internationl Review of Theology, Petrópolis, RJ: Vozes, n. 367, p. 13-24, 2016.

BAUMAN, Zygmunt. Globalização: as consequências humanas. Rio de Janeiro: Jorge Zahar, 1999.

BAZÁN, Víctor. Perfiles y exigencias actuales del estado de derecho. Quito: Konrad Adenauer Stiftung, 2008.

BIX, Brian H. Diccionario de teoría jurídica. Cidade do México: Unam, 2009.

BOBBIO, Norberto Bobbio; MATTEUCCI, Nicola; PASQUINO, Gianfranco. Dicionário de política. 11. ed. Brasília: Universidade de Brasília, 1998. 
BRASIL. Lei no 8.078, de 11 de setembro de 1990. Código de Defesa do Consumidor. Dispõe sobre a proteção do consumidor e dá outras providências. Disponível em: http://www.planalto.gov.br/ccivil_03/Leis/L8078.htm. Acesso em: 12 jul. 2019.

CARVALHO, Mário. Religião e relação de consumo. Disponível em: https://mariocarvalhoadv.jusbrasil.com.br/artigos/137105591/religiao-e-relacao-de-consumo. Acesso em: 17 maio 2019.

CAVALIERI FILHO, Sergio. Programa de direito do consumidor. 2. ed. São Paulo: Atlas, 2010.

DWORKIN, Ronald. Religião sem Deus. São Paulo: Martins Fontes, 2019.

ESTADOS UNIDOS DA AMÉRICA. Constituição (1787). Constituição dos Estados Unidos da América. Disponível em http://www. direitoshumanos.usp.br/index.php/Documentos-anteriores-\%C3\%A0-cria\%C3\%A7\%C3\%A3o-da-Sociedade-das-Na\%C3\%A7\%C3\%B5es-at\%C3\%A9-1919/constituicao-dos-estados-unidos-da-america-1787.htmlhtm. Acesso em 11 jul. 2019.

FERREIRA, Luiz Pinto. Comentários à Constituição Brasileira. São Paulo: Saraiva, 1998.

FRANÇA. Declaração (1789). Declaração de Direitos do homem e do cidadão. Disponível em: http://www.direitoshumanos. usp.br/index.php/Documentos-anteriores-\%C3\%A0-cria\%C3\%A7\%C3\%A3o-da-Sociedade-das-Na\%C3\%A7\%C3\%B5es-at\%C3\%A9-1919/declaracao-de-direitos-do-homem-e-do-cidadao-1789.html. Acesso em: 11 jul. 2019.

JELLINEK, Georg. La declaración de los derechos del hombre y del ciudadano. Cidade do México: Unam, 2000.

MACHADO, Jónatas Eduardo Mendes. Liberdade religiosa numa comunidade constitucional inclusiva: dos direitos da verdade aos direitos dos cidadãos. Coimbra: Coimbra, 1996.

MARQUES, Cláudia Lima; MIRAGEM, Bruno. O novo direito privado e a proteção dos vulneráveis. 2. ed. São Paulo: Revista dos Tribunais, 2014.

MIRANDA, Jorge. Manual de Direito Constitucional. Tomo IV, direitos fundamentais. 3. ed. Coimbra: Coimbra, 2000.

MORAIS, Márcio Eduardo Senra Nogueira Pedrosa. Liberdade religiosa: o ensino religioso na Assembleia Nacional Constituinte de 1987-1988. Curitiba: Juruá, 2015.

MORAIS, Márcio Eduardo Senra Nogueira Pedrosa. Religião e direitos fundamentais: o princípio da liberdade religiosa no estado constitucional democrático brasileiro. Revista Brasileira de Direito Constitucional - RBDC, São Paulo, n. 18, p. 225-242, jul./ dez. 2011.

ROSANVALLON, Pierre. La democracia del siglo XXI. Revista Mexicana de Política Exterior, Cidade do México, n. 108, p. 148-162, set./dez. 2016.

SILVA, Ivan de Oliveira. Relação de consumo religiosa: a vulnerabilidade do fiel-consumidor e a sua tutela por meio do código de defesa do consumidor. São Paulo: Atlas, 2012.

SILVA, Ivan de Oliveira. Relação de consumo religiosa. Jornal Carta Forense. Disponível em: http://www.cartaforense.com.br/ conteudo/entrevistas/relacao-de-consumo-religiosa/8833. Acesso em: 14 jul. 2019.

SOLOMON, Michael R. O comportamento do consumidor: comprando, possuindo e sendo. 11. ed. Porto Alegre: Bookman, 2016.

VASAK, Karel. The International Dimensions of Human Rights. Paris: Greenwook Press, 1982.

VERBICARO, Dennis; ATAÍDE, Camille; ACIOLI, Carlos (coord.). Provocações contemporâneas no direito do consumidor. Rio de Janeiro: Lumen Juris, 2018.

VERBICARO, Dennis; RODRIGUES, Lays; ATAÍDE, Camille. Desvendando a vulnerabilidade comportamental do consumidor: uma análise jurídico-psicológica do assédio de consumo. In: VERBICARO, Dennis; ATAÍDE, Camille; ACIOLI, Carlos (coord.). Provocações contemporâneas no direito do consumidor. Rio de Janeiro: Lumen Juris, 2018. 